\title{
Ativismo judicial nas lutas da sociedade civil contra os transgênicos
}

\author{
Luiza Duarte Bissoli*
}

\begin{abstract}
Resumo: A proposta insere-se nas atuais discussões da teoria política contemporânea sobre democracia e participação, tendo em vista a transferência de demandas políticas das organizações ambientalistas para o poder judiciário. A partir de uma perspectiva genealógica estão sendo produzidas análises dos conflitos no tema dos transgênicos, identificando seus atores e o processo político anterior que culminou na judicialização ambiental. A metodologia parte do exame das Ações Civis Públicas (ACPs) e das Ações Diretas de Inconstitucionalidade (ADIns) constantes no Superior Tribunal de Justiça (STJ), e no Supremo Tribunal Federal (STF), a partir do ano 2000; e, da realização de entrevistas com atores das instituições envolvidas (Judiciário, Ministério Público e membros das organizações civis que utilizam das ações judiciais como repertório de ação). As ACPs e as ADIns configuram-se em importantes estratégias da sociedade civil na medida em que visam criar barreiras às decisões que fomentam os transgênicos.
\end{abstract}

Palavras-chave: transgênicos, ações judiciais, judicialização ambiental, Idec.

\section{Introdução}

0 artigo é fruto de uma pesquisa de iniciação científica que se propõe a analisar a judicialização dos conflitos no tema dos transgênicos a partir do processo de transferência das discussões ambientais acerca dos Organismos Geneticamente Modificados (OGMs) para o judiciário. A partir de uma perspectiva genealógica busca identificar os diversos atores, espaços e estratégias de atuação das organizações civis que ingressam com esse tipo de ação através de uma trajetória política pretérita que culminou na utilização desses recursos jurídicos.

A pesquisa está em andamento, e inicialmente realizou-se o levantamento documental e a análise de acórdãos de Ações Civis Públicas (ACPs) e das Ações Diretas de Inconstitucionalidade (ADIns) impetradas por organizações da sociedade civil, a partir do ano 2000, respectivamente, no Superior Tribunal de Justiça (STJ) e no Supremo Tribunal Federal (STF). Eventualmente, ações presentes em outras instâncias foram também analisadas nesta pesquisa. Em momento posterior do desenvol-

\footnotetext{
*Graduanda em Ciências Sociais - UFES. Faz iniciação científica sob orientação da profá. Cristiana Losekann, com apoio do Laboratório de Estudos Políticos (LEP) e financiamento do CNPq.
} 
vimento desse subprojeto, serão feitas entrevistas, em profundidade, com os atores envolvidos nesses processos.

Neste momento analisaremos uma ação civil pública específica, de registro "AC n 2003.34.00.034026-7/DF", que se encontra no site do Ministério Público Federal (cf. <www.pgr.mpf.gov.br $>$ ), impetrada pelo Instituto Brasileiro de Defesa do Consumidor (Idec) contra a União Federal e o Estado do Rio Grande do Sul. Nesta ACP os réus são acusados de se omitirem na fiscalização dos agrotóxicos aplicados em soja transgênica, sem coibir seu uso ilegal.

No geral, para o desenvolvimento do texto utilizamos Santos (2007), que questiona a não-participação da sociedade civil no conselho da CTNBio e o papel da ciência. São citados alguns marcos jurídico-legais relativos ao meio ambiente durante toda a construção do texto, tais como o próprio art. 225 da nossa Constituição Federal, dentre outros. Busca-se também em McAdam, Tarrow e Tilly (2009), Bringel e Falero (2008) e Tarrow (2009) um aporte teórico para compreender os movimentos sociais e, em Escobar(1999) e Bringel e Falero (2008), o conceito de redes.

\section{Breve histórico da luta antitransgênicos}

Na última década do século XX e no início do século XXI vimos no Brasil o surgimento de um embate sobre a liberação dos OGMs (RIBEIRo; MARIN, 2012). Em 2005 a Lei de Biossegurança (Lei no 11.105/05) foi aprovada, o que significava o fim da necessidade das licenças ambientais para estudo das OGMs. Com a lei foi reestruturada a Comissão Técnica Nacional de Biossegurança (CTNBio), que não permite a participação de organizações ambientalistas em seu conselho, e julga, sozinha, os pedidos de liberação do uso comercial das sementes transgênicas. Nem o Ministério do Meio Ambiente (MMA) opina nessas questões.

A partir da análise de diversos acórdãos de ACPs e de ADIns percebe-se que o fato de permitir somente à CTNBio aprovar ou não o plantio de organismos geneticamente modificados, e retirar da sociedade civil o direito de influenciar nessas decisões sobre a aprovação ou não do plantio dos transgênicos, aumenta a discussão entre os vários setores organizados do país, como as ONGs e o próprio Ministério Público. Em espaços participativos, diversos atores do MMA e da sociedade civil discutiram sobre a liberação da pesquisa e da comercialização de OGMs, antes mesmo da aprovação da Lei no $11.105 / 05$, e defenderam que a agricultura envolvendo a transgenia precisava ser feita com muita cautela. 
Esta posição foi definida, por exemplo, em deliberações na I Conferência Nacional de Meio Ambiente (I CNMA) e na Resolução no 305/2002, do Conselho Nacional de Meio Ambiente (CONAMA), que dispôs sobre requisitos para empreendimentos que envolvem biotecnologia, incluindo o acesso às informações pertinentes para a população e o controle do órgão ambiental. Além disso, quando ainda Ministra do Meio Ambiente, Marina Silva assinou o Protocolo de Cartagena, na Colômbia, em que o Brasil se comprometia a resguardar diversos procedimentos em relação à biossegurança (LoSEKANN, 2012).

A questão de risco tornou-se tão importante que foi objeto de intensa luta política em vários foros internacionais na década de 1990, quando a sociedade percebeu que os problemas tecnocientíficos não poderiam ser deixados, exclusivamente, nas mãos da tecnociência. O Brasil, por exemplo, é signatário da Convenção sobre Diversidade Biológica (CDB), que diz no artigo 15: “Onde há risco de séria ou irreversível destruição, a falta de certeza plena dos cientistas não pode postergar medidas preventivas para devastação ambiental. Trata-se do chamado Princípio de Precaução, que está presente no Protocolo de Cartagena".

Outro ponto crucial a ser levado é consideração é o artigo 225 da Constituição Federal de 1988 que fala sobre o direito à biodiversidade e eleva o meio ambiente equilibrado à categoria de bem jurídico (SANTOS, 2007). Muitas convenções das quais o Brasil é signatário, resoluções criadas em órgãos públicos e outras instituições, legislações, e diversos instrumentos jurídicos consagram o princípio da precaução.

No entanto, mesmo com todos esses marcos jurídicos e muitos outros, para Santos (2007) a tecnociência acredita estar acima dessas convenções, leis, constituições, declarações e diversos outros mecanismos institucionais-legais presentes nessa mesma sociedade que a questiona. Assim, a tecnociência frequentemente ignora os interesses externos aos seus objetivos desenvolvimentistas. Para este autor, a Lei de Biossegurança é um exemplo disso, quando uma aliança entre o agronegócio, parcela da comunidade científica e as transnacionais das "ciências da vida" visavam a transformação dessa mesma lei em uma lei de fomento à biotecnologia. Lei para o desenvolvimento a qualquer preço, a partir uma moldura jurídica que permitisse o não limite à pesquisa e à comercialização da engenharia genética.

Numa lógica contrária ao que ocorre em países europeus, onde são constituídos comitês para reunir setores interessados em discutir opções tecnológicas antes 
de qualquer decisão política, no Brasil cientistas e empresários ruralistas tentam impedir inclusive o Ministério do Meio Ambiente de dispor de qualquer instância de tomada de decisão (SANTos, 2007).

Proibidos de participar ativamente nas decisões sobre os transgênicos nos âmbitos Executivo e Legislativo, a exploração da arena política por parte das organizações civis passou dos limites institucionais-partidistas para abarcar espaços, identidades e formas de ação coletiva desenvolvidas no seio da sociedade civil (BRINGEL; FALERO, 2008). Podemos ver um exemplo de uma dessas possibilidades a partir do caso do Instituto Brasileiro de Defesa do Consumidor (Idec), bem como de uma ação pública específica movida por este contra a União Federal e o Estado do Rio Grande do Sul, conforme segue abaixo.

\section{O Idec e a luta contra os transgênicos}

Fundado em 1987, o Idec é uma associação de consumidores sem fins lucrativos, desvinculada de empresas, governos ou partidos políticos. É mantida com recursos financeiros provenientes de contribuições dos associados, da assinatura da Revista do Idec e demais publicações, além da realização de cursos. 0 Instituto recebe apoio de organismos públicos e fundações independentes, e justifica que esses recursos não comprometem sua independência. 0 Idec tem assento no Consumers International, organismo internacional que congrega mais de 250 associações de consumidores ao redor do mundo, faz parte do Fórum Nacional das Entidades Civis de Defesa do Consumidor (FNECDC), da Associação Brasileira de Organizações Não-Governamentais (Abong) e de várias redes temáticas nacionais e internacionais.

O Idec atua em muitas questões ligadas ao consumidor, que envolvem desde problemas de consumo em ambientes urbanos até prejuízos ambientais (IDEC, 2012a).

Uma das bandeiras mais conhecidas é a defesa da rotulagem de alimentos que contêm OGMs. É um mecanismo regulado pelo Decreto 4.680/03, que diz que os fabricantes devem indicar quando o alimento contém mais de 1\% de OGM em sua composição, mesmo que não identificado no produto final. 0 rótulo deve conter 0 símbolo "T" inserido no meio de um triângulo amarelo, além de uma frase de alerta. A luta começou em 1999 e demorou quase oito anos até que uma sentença favorável fosse concedida à ACP do Idec e do Ministério Público Federal, determinando que 
"os alimentos com qualquer quantidade de transgênicos devem conter alerta no rótulo e que a União deve fiscalizar as empresas" (IDEC, 2012e, p. 14).

Outro instrumento utilizado pelo Idec foi uma carta enviada aos deputados federais para impedir a aprovação Projeto de Lei (PL) 4.148/08, de autoria de Luiz Carlos Heinze (PP/RS), contrário à rotulagem de alimento, em parceria com 28 organizações civis, entre as quais a Assessoria e Serviços a Projetos em Agricultura Alternativa (ASPTA) e Greenpeace (IDEC, 2012b).

O Idec ainda produziu uma cartilha e participou de eventos internacionais, em um deles elaborando, com outras organizações, uma carta política. A cartilha, intitulada "Transgênicos: feche a boca e a abra os olhos", foi feita para orientar os consumidores sobre os produtos transgênicos dentro de um projeto coordenado pela Consumers International, com apoio da Comunidade Europeia e parceria do FNECDC e da campanha por um Brasil livre de transgênicos (IDEC, 2012c).

No segundo caso, o Idec participou de um evento em Curitiba, no ano de 2009, para debater junto com representantes de 80 organizações de movimentos sociais, de ONGs e de entidades de defesa do consumidor de todo país, a situação dos transgênicos e seus impactos sobre a biodiversidade, a saúde pública e os direitos de agricultores e consumidores. Divulgaram carta política após o evento, que defendeu a agricultura familiar camponesa de base ecológica (IDEC, 2012d).

A partir dessas informações nota-se que o Idec atua em redes transnacionais e nacionais, com parcerias, filiações e/ou apoios do Greenpeace, do Consumers International e da ASPTA, apenas para citar algumas organizações. Essas relações podem ser estudadas dentro dos conceitos de redes (EscobAR,1999; McAdAM; TARRow; Tilly, 2009; Tarrow, 2009; Bringel; Falero, 2008), e também nas abordagens que tratam de conceitos como ação coletiva, repertórios de ação e quadros interpretativos, dentre outros (MCADAM; TARRow; TILLY, 2009; TARROW, 2009; BRINGEL; FALERO, 2008).

Como antagonismos podemos citar a União Federal e o Estado do Rio Grande do Sul [no caso específico da ACP tratada a seguir], as redes de apoio aos transgênicos [centros de pesquisa de biotecnologia, transnacionais como a Monsanto, etc.] e congressistas da bancada ruralista, tais como o deputado Luiz Carlos Heinze (PP/RS) e a senadora Kátia Abreu, que em 2007 propôs um Projeto de Decreto Legislativo (PDL) de no 90/2007 contra a rotulagem de alimentos transgênicos. 


\title{
Ação civil pública contra o Glifosato
}

Trata-se de uma ação civil pública movida pelo Idec contra a União Federal e o Estado do Rio Grande do Sul, em 2003. O objeto foi impedir e proibir a utilização do agrotóxico glifosato em soja transgênica. A primeira sentença indeferiu a ação, alegando que não havia "o interesse em propor uma ação com a finalidade de resultar impedimento de um dano" (JuSBRASIL, 2012). O Instituto recorreu argumentando a existência "desse mesmo interesse", uma vez que o Idec requer a efetiva fiscalização do uso do defensivo agrícola supracitado. 0 proponente apelou, ou seja, a ação passou para instância superior. Assim, apenas a critério de breve menção, os réus passaram a serem os apelados e o Idec, o apelante.

Um dos argumentos centrais dessa ação está no presente seguimento:

\begin{abstract}
Inconstitucionalidade das Leis 10.688/03 (oriunda da conversão da Medida Provisória 113/03), 10.814/03 (oriunda da conversão da Medida Provisória 131/03) e 11.092/05 (oriunda da conversão da Medida Provisória 223/04) (PARECER, AC nº 2003.34.00.034026-7/DF) (Distrito FEDERAL, 2008).
\end{abstract}

Tais leis consideradas inconstitucionais pelo Idec (anteriormente medidas provisórias) liberaram a utilização e a comercialização da soja transgênica, resistente ao agrotóxico glifosato, sem passar por Estudos de Impacto Ambiental (EIA). O Idec argumentou que tal medida privilegia o interesse econômico de poucos, sem levar em consideração os possíveis prejuízos causados ao meio ambiente e aos consumidores dos produtos submetidos a altas doses de defensivos agrícolas.

Para corroborar esse argumento, o apelante utiliza de vários embasamentos jurídicos. Inicialmente expõe o art. 225 da Constituição Federal (CF) que trata do Meio Ambiente, focando no inciso 1ํ, IV sobre o Princípio de Precaução, no que tange a ausência de EIA nas plantações desses organismos geneticamente modificados. Outro ponto, também referente ao art. 225 da CF, trata do papel do Estado em conscientizar, educar, orientar e prestar esclarecimentos à sociedade sobre a preservação do meio ambiente.

Além disso, o Idec aponta inconstitucionalidade na Lei de Biossegurança, retomando, mais uma vez, a necessidade do EIA/RIMA (Estudo de Impacto Ambiental - Relatório de Impacto Ambiental), e questionando, inclusive, o fato da CTNBio ter exclusividade nas decisões que aprovam a liberação das sementes transgênicas: 
Inconstitucionalidade, ainda, da atual Lei de Biossegurança, [...] 0 mesmo se observa no art. 16, $3^{\circ}$ [...] ao conferir à CTNBio a possibilidade de deliberar em última e definitiva instância sobre os casos em que a atividade seja potencial ou efetivamente causadora de degradação ambiental. Outro agravante decorrente dessa vinculação é a possibilidade de dispensa de prévio EIA/RIMA (Distrito FEDERAL, 2008).

O parecer da apelação foi emitido em 2008 pelo Ministério Público Federal, que foi favorável ao recurso do Idec. Argumentos da Exma. Procuradora Regional da República, Maria Soares Camelo Cordioli, dizem:

Tal permissividade, seguramente em prol de interesses econômicos, redundou em inaceitável desamparo do meio ambiente, dos direitos do consumidor e da saúde pública, na media em que mitigou, senão anulou, as regras que direcionavam o Poder Público na sua incumbência prevista nos II e V do $§ 1^{\circ} \stackrel{\text { do art. }}{225}$ da CF (DistRITo FEDERAL, 2008).

O parecer também critica a atual Lei de Biossegurança e a CTNBio, uma vez que outros órgãos não possuem as possibilidades de licenciar sobre atividades potencialmente prejudiciais ao meio ambiente, além de permitir a dispensa de prévio EIA/RIMA. Assim, finaliza:

Pelo exposto, razão assiste ao apelante em todos os pedidos por ele formulados, sobretudo, por tratar-se de valores maiores, quais sejam a efetiva proteção à saúde e a vida da população, bem como a devida proteção ao meio-ambiente. [...] a conduta omissiva e permissiva das rés acabam por criar um cenário de notória afronta aos princípios constitucionais de defesa do consumidor e do meio-ambiente (DISTRITo FEDERAL, 2008).

\section{Direitos ambientais e (bio)diversidade}

Bringel e Falero (2008) observam que os direitos foram construídos dentro de transformações que promoveram o surgimento da modernidade europeia, com a criação do Estado-Nação. Já em 1945, com vários Estados-Nações consolidados, foi fundada a Organização das Nações Unidas (ONU), pessoa jurídica de Direito Público Internacional com a finalidade de efetivar os direitos da pessoa humana, que elaborou a Declaração Universal em 1948, documento internacional que inspirou a elaboração de inúmeras constituições, inclusive a CF de 1988 (SouzA, 2009).

Décadas depois surgiu no cenário internacional outra questão: a degradação ambiental. Esta trouxe em seu bojo um ponto crucial: a maior biodiversidade do planeta encontra-se majoritariamente nos chamados países economicamente em desenvolvimento. Em defesa do meio ambiente o conceito de desenvolvimento sus- 
tentável foi criado no Relatório Brudtland, e posteriormente elaboradas as declarações de Estocolmo/72 e do Rio/92 (SouzA, 2009). Vale lembrar que recentemente, em junho de 2012, ocorreram a RIO+20 e a Cúpula dos Povos, na cidade do Rio de Janeiro, corroborando com o tom do discurso ambientalista em âmbito mundial. Neste processo o Direito Ambiental passou a ser um Direito fundamental, classificado inclusive no Direito brasileiro, pelo Ministro Celso de Mello, como um direito humano de terceira geração (ver mais em STF, MS 22.164).

Vemos, portanto, que com o passar dos anos, a demanda pela preservação do meio ambiente atingiu o status da maturidade, inclusive compondo a Constituição Federal brasileira em vigor, que dedica o art. 225 para o tema ambiental, conforme comentado anteriormente.

Neste cenário de proteção à biodiversidade e ao meio ambiente como um todo surgiu a valorização de populações ligadas diretamente à exploração dos recursos naturais, muitas vezes comunidades tradicionais que detém saberes populares, comumente chamados de "conhecimento tradicional". Este conceito ganhou, inclusive, aspecto legal há pouco mais de dez anos, como consta na Medida Provisória no 2.186-16/01.

Em consonância com essa lógica, deve ser novamente citada a CDB, assinada pelo Brasil. A CDB une dois vieses: o ambiental e o saber local, tratando inclusive sobre o respeito e valorização do conhecimento tradicional (SHIVA, 2003).

\section{Resultados, impactos e significados das ações judiciais e a transnacionalização do movimento ambiental}

A defesa ao meio ambiente surgiu primeiramente em círculos sociais menores por meio da formulação de novas ideias, que passaram a ser compartilhadas amplamente em círculos cada vez maiores. Conforme destacado anteriormente, novas redes de relações se forjaram através de diversos debates internacionais, eventos realizados, ações de ONGs, propagandas conceituais, movimentos civis ao redor do mundo e outras formas de manifestação, inclusive em períodos de intensa atividade como a Rio 92 e a Cúpula dos Povos, em 2012. E, nesses processos, vários objetivos foram/são frequentemente institucionalizados e transformados em leis/legislação.

Segundo McAdam, Tarrow e Tilly (2009), o terreno analítico dos movimentos sociais possui fronteiras fluidas, podendo envolver diversos atores e repertórios de ação. Tendo em conta que o movimento ambiental busca inviabilizar decisões 
contrárias ao Meio Ambiente de diversas maneiras, muitas das quais não tratadas neste artigo, pode-se considerar as ações judiciais de cunho ambiental como parte dos quadros interpretativos de ação coletiva utilizados pelas organizações civis ambientalistas, e até mesmo pelo Ministério Público, como recursos de "retificação" e efetividade de processos participativos. Tanto é que as ações judiciais entraram como forte instrumento para barrar as decisões de fomento aos transgênicos, muitas vezes como último recurso após lutas em diversas instâncias.

Mesmo assim, apesar dos diferentes repertórios de ações (das articulações, das ferramentas institucionais e, claro, das ações judiciais muitas vezes bem sucedidas como forma de atuação das ONGs nacionais) há um quadro acelerado de aprovação dos produtos transgênicos no Brasil. Dados de relatórios do ISAAA (do inglês The International Service for the Acquisition of Agri-biotech Applications) demonstram que o país ocupa hoje a $2^{\mathrm{a}}$ posição em área de plantio desses alimentos modificados geneticamente e aprovou diversas sementes nos últimos anos (JAMES, 2011).

Muitos ambientalistas, organizações e estudiosos na área, parte deles citados durante o texto, têm se manifestado contrários ao chamado redutivismo genético promovido pela aprovação e plantio irrestrito dos OGMs ao redor do mundo, inclusive porque não passam pelo crivo da participação da sociedade civil (no caso da CTNBio) e, constantemente, não são realizados estudos de impacto, em acordo com as declarações e legislações vigentes.

Esse quadro em que os resultados gerais são constantemente desfavoráveis às ONGs ambientais e à sociedade no geral, tanto no Brasil, quanto no mundo, tem gerado redes transnacionais envolvendo atores globais. A biodiversidade cria uma rede transnacional que envolve diversos atores, práticas, culturas e interesses, em que "a identidade de cada um dos atores afeta a rede e é afetada por ela" (EscoBAR, 1999, p. 16; tradução nossa). Na parte dominante dessa rede estão as ONGs, os jardins botânicos, as companhias farmacêuticas e os cientistas, que produzem "verdades" muitas vezes questionadas pelos movimentos sociais. Do lado contrário estão, constantemente, os discursos de soberania nacional, das ONGs progressistas e dos movimentos sociais.

Bringel e Falero (2008) ressaltam que tais lutas e movimentos sociais que ocorrem em âmbito transnacional não podem ser desvinculados de lógicas doméstico-nacionais. Há, ao mesmo tempo, uma dinâmica reticular transnacional e uma forte base territorial no espaço da nação. 0 que une esses movimentos em plano 
internacional são convergências de solidariedade e identidades, marcos que transcendem o local-nacional.

Esses movimentos sociais mostram como é possível organizar a vida, o trabalho, a natureza e a cultura fora dos conceitos fechados emanados por uma cultura padronizada e uma economia exploratória (EscoBAR, 1999).

\section{Considerações finais}

Conforme destacado neste artigo, as organizações civis ambientalistas ao redor do mundo atuam hoje, tanto nacional quanto internacionalmente, formando uma rede transnacional que utiliza diversos repertórios de promoções para gerar ações coletivas. No Brasil uma das ferramentas de ato político que tem ganhado relevância é a via judicial: as ACPs e ADIns, contra as decisões que fomentam os transgênicos.

Além disso, vale ressaltar que o papel da CTNBio, como única e definitiva instância que aprova os OGMs, promove críticas variadas constantes em diversas partes do texto. Esta crítica pode ser notada de forma indireta nos conteúdos de muitas ações judiciais, dentre as quais a do Idec presente no artigo, que defendem a participação de membros da sociedade nas decisões sobre transgênicos.

Por fim, apesar de as análises estarem ainda em via de produção, podemos concluir que as ACPs e ADIns, muitas vezes inacessíveis ao chamado público comum devido ao processo judicial envolvido que demanda um certo conhecimento dos aparatos legais, configuram-se num repertório de ação a mais para compor os quadros interpretativos da ação coletiva. Muitas atuando como possível forma de contorno de processos já aprovados em instâncias executivas e legislativas, e para suprir certas ausências ou ineficácias dos espaços participativos.

\section{Referências}

Bringel, B. FAlERo, A. (2008). "Redes transnacionais de movimentos sociais na América Latina e o desafio de uma nova construção socioterritorial". Caderno CRH, Salvador, v. 21, n. 53, p. 269-288, maio/ago.

Distrito Federal (2008). Ministério Público Federal - Procuradoria Regional Da República 1aㅡ Região. Ação Civil Pública AC n²003.34.00.034026-7/DF. Apelante: Idec. Apelado: União Federal e Estado do Rio Grande do Sul. Relator: Desembargador Federal Souza Prudente. Brasília/DF, 8 de fevereiro de 2008. Disponível em: <http://4ccr.pgr.mpf.gov.br/institucional/grupos-de-trabalho/gt-transgenicos/ acps/acp SojaTransgenica.pdf>. Acesso em: 11 nov. 2012. 
Escobar, A. (1999). "Comunidades negras de colômbia: en defensa da biodiversidad, território y cultura”. Biodiversidad, n. 22, p. 15-20, Dec.

FERES JÚNIOR, J.; PogrebinsChI, T. (2010). Teoria política contemporânea: uma introdução. Rio de Janeiro, Elsevier.

IDEC (2012a). O que é. Disponível em: <http://www.idec.org.br/o-idec/o-que-e>. Acesso em: 7 ago. 2012.

. (2012b). Idec assina monção contra mais restrições na rotulagem de transgênicos. Disponível em: <http://www.idec.org.br/em-acao/em-foco/idec-assina-mocao-contra-mais-restricoes-na-rotulagem-de-transgenicos $>$. Acesso em: 7 ago. 2012.

. (2012c). Idec lança cartilha de alerta sobre os riscos dos transgênicos. Disponível em:<http://www.idec.org.br/em-acao/em-foco/idec-lanca-cartilha-que-alerta-sobre-os-riscos-dos-transgenicos >. Acesso em: 7 ago. 2012.

(2012d). Idec e entidades defendem agricultura familiar e fiscalização dos transgênicos em carta política. Disponível em: <http://www.idec.org.br/em-acao/ em-foco/idec-e-entidades-defendem-agricultura-familiar-e-fiscalizacao-dos-transgenicos-em-carta-politica>. Acesso em: 7 ago. 2012.

(2012e). Linha do tempo. Disponível em: <http://www.idec.org.br/uploads/ publica\%20coes/publicacoes/Linha do tempo web.pdf>. Acesso em: 7 ago. 2012.

JAMES, C. (2011). “Situación mundial de la comercialización de cultivos biotecnológicos/ MG en 2011". ISAAA, n.43.

JuSBrasil (2012). Interesse de agir. Disponível em: <http://www.jusbrasil.com.br/ topicos/292164/interesse-de-agir>. Acesso em 20 ago. 2012.

LosEKANN, C. (2012). "Participação da sociedade civil na política ambiental do governo Lula”. Ambiente \& Sociedade, São Paulo, vol. XV, n. 1, jan-mai, p. 179-200.

McAdam, D.; TARrow, S.; Tilly, C. (2009). "Para mapear o confronto político". Lua Nova, São Paulo, n. 76, p. 11-48.

Ribeiro, I. G.; MARIN, V. A. (2012). “A falta de informação sobre os Organismos Geneticamente Modificados no Brasil”. Ciência \& Saúde Coletiva, Rio de Janeiro, vol. 17, n. 2, fev.

SAnTos, L. G. (2007). "Desencontro ou "malencontro": os biotecnólogos brasileiros em face da sócio e da biodiversidade". Novos Estudos - Cebrap, São Paulo, n. 78, p. 49-57, julho.

ShIVA, V. (2003). Monoculturas da mente: perspectivas da biodiversidade e da tecnologia. São Paulo, Gaia. 
SouzA, H. M. (2009). "Direitos humanos, conhecimentos tradicionais e propriedade intelectual. Uma análise zetética e dogmática". Jus Navigandi, Teresina, ano 14, n. 17, mar. Disponível em: <http://jus.com.br/revista/texto/12479>. Acesso em: 4 ago. 2012.

TARrow, S. (2009). O poder em movimento: movimentos sociais e confronto político. Petrópolis, Vozes.

Recebido em dezembro/2012

Aprovado em janeiro/2013 